\title{
Research Paper: Participatory Planning and Integrated Water Resources Management: A Case Study of the Eastern Rural Areas of Iran
}

\author{
Mostafa Taleshi $^{1^{*}}$
}

1. Associate Professor in Geography \& Rural Planning,Geography Department Payame Noor University, Tehran, Iran.

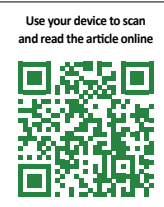

Citation: Taleshi, M. (2018). Participatory Planning and Integrated Water Resources Management: A Case Study of the Eastern Rural Areas of Iran. Journal of Sustainable Rural Development, 2(1-2), 29-38. https://doi.org/10.32598/jsrd.01.03.290

d. ${ }^{*}:$ https://doi.org/10.32598/jsrd.01.03.290

Article info:

Received: 28 April 2018

Accepted: 15 July 2018

\section{Keywords:}

Participatory planning, Rural communities, Integrated management, Water resources, Rural areas in the East of Iran, Sustainable development

\section{A B STRACT}

Purpose: One of the main challenges of water resource management in rural areas, especially in arid and semi-arid regions of Iran, is the disconcerted management in governmental executive departments, including the Water Supply Organization, which is an executive department under the Ministry of Energy, and the Department of Policy Management and Operations, which is affiliated to the Ministry of Agriculture. There are also rural water users who play a role in this challenge. They are actually the rural communities in different forms and compositions with different production methods in the popular sector.

Methods: Documentary and field studies were conducted to examine the role of participatory planning in integrated water resources management on the purpose of achieving sustainable rural development.

Results: In a systematic approach to water resources, which always calls for integrated water resources management, there is a loop of connections among the required actors and forces. Participatory planning by designing livelihoods and sustainable production patterns (i.e. using the methods and techniques of the participatory planning of local communities), and the establishment and strengthening of facilitation systems make good links in the integrated management of water resources in rural areas.

Conclusion: The results of the studies carried out in eastern Iran, including the provinces of northern Khorasan, Khorasan Razavi, South Khorasan and Sistan and Baluchestan, indicate that informed, all-inclusive, and rural-based participatory techniques and facilitation measures in organizations and systems within the framework of participatory planning techniques can facilitate the achievement of a sustainable approach to integrated water resources management, which ultimately achieves more success in sustainable rural development. 


\section{Introduction}

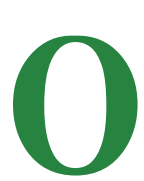

ne of the challenges facing territorial management systems in many developing countries, including Iran, is the water resource crisis. This crisis has been occurring over the years due to the inefficiency of the management system and the disruption of the institutions involved in the production, conservation and utilization of water resources

Global Water Partnership (GWP) movements consider the water crisis as the result of inefficient management as well as ineffective legislation and institutions. They recommend an integrated water resource management (IWRM) approach to deal with the crisis. The achievement of an integrated water resources management system in the first step involves the use of participatory planning. This requires an accurate understanding of the concepts of social development through the understanding of individual and community empowerment approaches, the principles of facilitation, and rules and governance.

By this conceptual framework of planning, the integrated management of water resources in Iranian territories requires the use of the techniques of participatory planning at macro and micro levels as reported in the literature. In this regard, one should consider the characteristics of the natural environment of Iran, which mainly consists of dry and semi-arid regions, the socioeconomic characteristics of rural communities, and the current planning system. At the macro level of the management system for the production and supply of water resources, the management of policy making and operating methods should be done with organizational and inter-organizational coherence. The principles of participatory planning should also be put to practice through cooperative systems (i.e. facilitating system) and integrated Policies. Then, at the micro level, the conservation and the sustainable exploitation of water resources should be targeted in a purposeful manner and through dialogues, social co-operation, and the synergetic power of communities.

The ecological features and conditions in the geography of Iran, as a basis for producing and supplying water resources, provide an annual average precipitation of about 240 millimeters, which is about one-third of the world and half of Asia's average. Thus, dry and semi-arid ecological conditions are associated with limited and disproportionately distributed precipitation (Pourazagersingchin, 2004). Because the northern and western regions take a bigger share of water, about $70 \%$ of the high-quality water exists in these areas. The other half of the country has $30 \%$ of the resources in the central, eastern and southeastern regions (Abbaspur, 2003).

Recent research findings on the water resources of the country, especially on the balance of the input and output components of water resources in the country, indicate a water reserve of 3.8 billion square meters, which is more related to underground water reservoirs. Considering such a water deficit and increasing consumption as well as and the specific findings and predictions about water resources in 2022, the magnitude of the crisis and its prospective social and economic impacts become more understandable. Analytical results show that an average annual precipitation of about 400 billion square meters is extractable, about 270 billion square meters evaporates, 130 billion square meters is renewable as surface water, and 38 billion square meters of underground water can be used. In the analysis of water consumption in 2006 and 2016 and in the forecast for 2022, the conditions can be evaluated. According to the studies on this issue, the consumption of drinking water has increased from 5.5 billion square meters in 2006 to 7.5 Billion in 2016. This change has been from 1 billion to 1.5 billion square meters in the industry and mining sectors and from 97.7 billion to 103 billion square meters in agriculture (Jamab Co., 1999).

An analysis of the consumption and predictions suggest that, by managing the supply and development of water resources for the year 2022 based on ongoing projects and adequate funds, only 113 billion square meters can be obtained (Macnon, 2003). Hence, according to the estimated total consumption in 2022, with an increase of approximately $20 \%$, the total required water will be 134.4 billion square meters. In other words, a deficit of more than 21 billion meters is predictable, suggesting that the crisis will be intensified from 2019 (i.e. current situation). Of course, the most critical condition is in the agricultural sector, or somehow in the rural sector. The need for an integrated approach of water resource Management in rural areas is becoming more and more obvious. There is a set of symptoms for the emergence of water resource crises, especially in rural areas. It has caused water scarcity in agriculture, which can lead to increasingly socio-economic crises such as rise of unemployment and rural-urban migrations but reduction of agricultural production and the stability of rural settlements.

Recognition of the causes of rural crises and their effects on water resources in rural areas as well as the ty- 
pology and position of agricultural utilization systems is of great importance. Peasant exploitation system, as a dominant model in rural areas, exacerbates the crisis of water resources due to its small size and agronomic dispersal, prolonged travel between farms and water resources. This decreases irrigation efficiency and degrades agro-exploitation methods. Over the decades before and after the revolution, water resources have been exploited through the establishment of corresponding systems and regulations under the supervision and administration of the government. Looking at the water system management in rural areas, one can see three distinct levels of management including water supply, distribution and use. Because of the government's dominance at each of these levels and imbalanced and biased sectoral policies, frequent crises have occurred in the exploitation and the proper management of water resources. Of course, in the history of water resource utilization systems in rural areas, collaborative exploitation experiences can also be traced; the traditional exploitation system has been run by supplying water resources to the owner or owners and managing the distribution and consumption in a partially collaborative way.

The results of relevant research show that, in the past, weeds, water loggers, and other components and factors of production were responsible for managing water distribution on behalf of farmers, and the management of consumption was the responsibility of the owner of the farm, either in group or individually (Azkia, 2014). Thus, there is evidence for the patterns of participatory systems in either rural or suburban areas, which is a clear indication of using the participatory planning approach by rural communities and the lesser involvement of public sector management. This discussion brings up the question as how integrated rural water resources management can be best achieved through participatory planning techniques.

\section{Literature Review}

The issue of people's participation in development plans dates back to the 1970s. Since the late 1970s, two parallel trends have been in question. On the one hand, there has been disappointment with the inconsistency of development plans and the realities of local communities increasingly expressed in official and scientific societies. Development processes have been subject to plans and projects that non-native experts design based on superficial knowledge of local realities. On the other hand, the existing experience in some parts of the world suggests that the ability of people to participate in development processes is far more than what is thought to be.
Local people are now considered as sources with deep and detailed knowledge of their living environment.

These two trends have led to the emergence and expansion of approaches that provide a more favorable context for active participation of people in the process of collecting and managing information. In order to get an image of the local community, the plans should be based on the findings of studies and on closer relationship with different dimensions of living and livelihoods (Musavi Nejad, 2004). In the new approach, there is no longer a development broker or a partner. People are the subjects and the creators of their lives, not the subjects of decision-makers. In this participatory process, the issue of control and ownership is taken into consideration in relation to decisions and the fate of the people. This is a collaborative and sustainable development process. At the same time as this change in traditional approaches and attitudes, it has emerged that one of the main obstacles to development in general is the lack of clarity and disparity in the development of local communities. The obvious feature of such planning is the lack of attention to people and the participation of villagers in their own affairs. Instead of being the main actors and agents of development, operators have become the passive recipients of thoughts and services and have been caught up in the backdrop of a complex system of state bureaucracy. In other words, their spontaneous movements and great abilities have been ignored in various ways.

Thus, participatory planning came into being as a product of dissatisfaction and failure and was created in the process of central planning. The first change it made was the acceptance of the fact that local people have a detailed knowledge of the environment, which may be ignored by external planners and experts. The second change was the recognition and acceptance of the fact that there are skills in local communities that planners, as specialists in development and planning, may not know all about. In addition to the recognition of the role of people and local communities in their affairs, the concept of partnership acquisition has undergone a fundamental transformation. The necessity of paying attention to the opinions of local people as a suitable solution to their problems is, nowadays, more widely recognized because it is accepted that locals and villagers have a clear understanding of their own situation. If the goal is sustainable development, they should be engaged in this issue.

At the same time, with the change in participatory programs, other mechanisms were devised to ensure full participation. Those mechanisms include changes in 
methods and planning, rather than methods and procedures for accurate data collection. Since the late 1980s, a set of participatory evaluation approaches, especially in rural participation (PRA), has been set up to enable people to explain and analyze their living conditions, plan their actions, and monitor and evaluate them. These approaches, if implemented properly, can provide the ground for local people to increasingly take control of their lives and resources and take actions to change their social and economic situation. At the beginning, participatory approaches (e.g. PRA and RRA) required rapid rural assessment and participatory rural evaluation. Major attention was paid to the active participation of local people in the realization of a comprehensive or realistic estimate for local life and environment. However, this partnership gradually increased until, in addition to analyzing the existing situation, it covered planning and operation for change and even monitoring and evaluation.

Based on the existing experiences, the idea of bottomup planning (i.e. participatory planning) entered the literature and inseminated different planning models. It actually introduced the idea of why plans should always be provided by a limited number of top-level ones and set as predefined versions sent to the lower levels, versions that local individuals and institutions have not only any role in their planning or designing but, more importantly, no authority to manipulate and change them. This is while economic and social conditions vary from region to region. Among those who have contributed to this field are Misra (1995) and Wight (1996). The latter is an expert in the implications of participation and its application in development. They have argued that there are two patterns of development in practice. The first is the traditional pattern favored in recent years and based on the theoretical debates of Venice Experiences gained from executive activities. The tenets of this pattern have already been seriously criticized. The modern approach to development, however, emphasizes the role of people in planning and its importance in the development process. It holds that development should not be imposed from outside the society, but it should be endogenous. Also, people are the active and creative elements in any development process. In both traditional and modern patterns of development, participation has a positive meaning, and the goals delineated for it derive from this positive connotation.

Part i cipatory planning is a set of processes through which different groups and desires interact in order to agree on a plan or a method. It can be initiated by each of the parties, and the difference between participatory and non-cooperative planning tasks, as in Table 1, is evaluable (Taleshi, 2006).

\section{Methodology}

Rreg arding the issue discussed in this research, and due to the limitations and failure of public sector management approaches as well as the insufficient achievement of rural communities to create local organizations thro $\mathrm{u}$ gh effective planning and institutionalization, participation in the integrated management of water resources requires a method to facilitate sustainable rural development. Hereby, the following requirements are set for this method:

- Due to the failure of some government executive programs in agricultural sustainable development and rural sustainable development, this method will be valid if non-governmental organizations are developed to guarantee the continuous, comprehensive and active participation of the rural.

- By using participatory planning techniques, increasing the capacity of rural communities to participate, and using facilitating approaches, the feasibility and success of executive water resources projects in rural areas should be analyzed and assessed.

- A s ustainable water resource partnership system should be designed in which to pursue sustainable rural development processes.

In th is research, participatory planning in integrated water resources management has been dealt with through documentary and field studies to achieve sustainable rural development.

In the documentary methodology, as the first step, the literature is reviewed to find a theoretical framework for a conceptual model of participation in the integrated water resources management.

Most of the existing studies on ecological conditions and social and economic characteristics in eastern Iran have focused on the rural development instability in that area. So, as the second step, in order to apply participatory planning techniques, four rural areas are chosen with regard to their ecological and socio-economic characteristics as well as developmental conditions.

In the third step, to assess the executive management system, local expert working groups are assessed for their facilitating capacity, and, in each rural area, the 
Table 1. Evaluation of participatory and non-participatory planning

\begin{tabular}{|c|c|c|}
\hline Participatory planning & Non-cooperative planning & $\begin{array}{l}\text { Evaluation crite- } \\
\text { rion }\end{array}$ \\
\hline Two-way communication & One-way communication & \\
\hline A large number of contributors & Extremely low number of contributors & \\
\hline the private and public sectors actors & Principal executive agents & \\
\hline Informal encounters & Formal encounters & Behavior \\
\hline Collaboration-based relationships & Conflicting relationships & \\
\hline Transparency & Hiding & \\
\hline Horizontal counseling / Internal mobility & Hierarchical authority & \\
\hline Participatory decision making & Focused decision making & \\
\hline Voluntary membership & Mandatory membership & \\
\hline Open borders & Closed borders & struccure \\
\hline Frequent and short interactions & inrequent and short interactions & \\
\hline Delegation of authorities & Restricted delegation of authorities & \\
\hline Volatile dynamic environments & Relatively static environments & \\
\hline Government supervision & Government domination & \\
\hline Government cooperation & The poor cooperation of the government with other sectors & \\
\hline $\begin{array}{l}\text { The limited freedom of the state in running } \\
\text { the society }\end{array}$ & The freedom of the state to act above the society & Context \\
\hline Distributed influence of interest groups & The inability of social groups to influence & \\
\hline Existence of balance among the actors & Lack of balance or symbiosis among the actors & \\
\hline Strong and active civil society organizations & Weak and non-active civil society organizations & \\
\hline
\end{tabular}

Taleshi (2016, p. 49)

functions and capabilities of the planning system are assessed too.

In the next step, through participatory planning techniques and expert working groups formed in the framework of rural development activities in each selected rural area, first of all, the main issues and problems of resource management in the agricultural sector are analyzed, and then a model is designed for participation in field operations.

In the final step of the study, the participatory system is considered in a network of non-governmental organizations intended to contribute to water resources and sustainable rural development.

In this study, the application of participatory plans in rural sustainable development has been selected based on traits of eastern Iran. The four rural areas were selected based on such features as ecological characteristics, water resource conditions, soil conservation, high and cat c hment basins, socio-economic status, distribution of rural population, and distribution of rural settlements. The selected areas were as follows:

- Central part of Faroj in North Khorasan Province

- Mashhad Plain in Khorasan Razavi Province

- Sarayan Area in South Khorasan Province

- Dashtak and Sefidabe villages in the county of Zabol, Sistan and Baluchestan Province

\section{Findings}

The Conceptual framework for integrated water resources management

In recent decades, the literature on development sustainability has been on a rise, and the issue has been discussed widely, as in the RIO International Summit. The result of the summit was the International Agenda 21. The eighteenth chapter of this document is dedicated to the sustainability of natural resources in general and to the storage of fresh water in specific. The document emp hasizes that the executive bodies of the member 
sta tes should support the quality and conservation of fresh water resources (Taravati, 1998). In other words, at this international summit, the concept of water resource management was established as an intersectional solution for the management of water resources. Together with this, a trans-organizational and managerial concept was introduced, and unsuccessful approaches to participatory management in general and the management of fresh water resources followed.

As the literature suggests, the principles of integrated water resources management were first laid down as the Dublin Principles in 1992. This protocol addresses such issues as the limitation of fresh water resources, application of comprehensive principles in water resource management, synchronization of social and economic development, conservation of resources and the environment, use of participatory development tools, increase of social awareness especially for women, and observance of the principles of the economic value of water (IWRM, 2004). In addition, the Global Water Partnership Program defines integrated water resources management as a process in which the coordinated development and management of water and soil resources and other related resources should be considered for the promotion of social and economic well-being in a fair manner and without sacrificing the sustainability of critical ecosystems (Calusen, 2005). In the first World Water Summit in 2000, the issue of integrated water resources management became more strategic; in fact, it was stated that managing integrated water resources is a fundamental and comprehensive strategy to find a favorable outlook for the environmental status of water and to meet agricultural, industrial, drinking and environmental needs. Finally, the United Nations Development Program (UNDP) defines the issue as a fundamental process for sustainable development, allocation and monitoring of water resources in social, economic and environmental fields.

The World Bank, as a development partner in protecting basic resources, especially water resources, in many developing countries, emphasizes the adoption of a framework for an integrated water resource approach. The necessity of frameworks must always be addressed in the management and development of water resources as well as other social, economic and environmental dimensions. Similarly, the Task Force on the Implementation of the Global Water Partnership Program (WFP) is also implementing integrated water resources management to fulfill the objectives of economic and social development in such a way that the sustainability of critical ecosystems, the future production of power, and the provision of water needs are not compromised (IWRM, 2004).

Conceptual frameworks for integrated water resources management have always been welcomed by the scientists, planners and executives that are concerned about damages to ecosystems, as in dry and semi-arid areas (Brown \& Lall, 2006; Engle et al., 2011; Ferreyra et al., 2008). Also, models for this management have been welcomed to provide a sustainable and comprehensive approach of increasing the life quality of communities, especially in rural areas, which are highly dependent on water economy.

Comprehensive and integrated water resource planning and management is a conscious and continuous participatory system that involves the participation of all stakeholders and decision-makers as well as wise ways of producing and distributing surface water and underground resources. It also organizes water consumption in drinking, industry, and agriculture, and has concerns for the environment in terms of socio-economic, environmental, legal and political conditions in compliance with the criteria and standards for the sustainability of water resources.

In other words, the purpose of integrated water resources management is to corroborate empowerment approaches and enhance the spirit of continuous participation of operators on one hand and to review and modify the approach of corporate governance on the other hand. So, certain ways are devised to regulate the governance structure, establish non-governmental organizations, and apply modern native technologies for the sustainable management of water resources.

Exploring the literature on the issue of integrated water resources management, one comes across some research efforts made in Iran too in this regard, which indicates the universally acceptable results of implementing such a scientific approach to water resource management. Zargarpour and Noorzad (2009) provided a conceptual model and formulated an integrated water resources management model with an emphasis on Iran's water security, integrated water and soil management, and integrated groundwater and surface water management.

In a study entitled 'Sustainability criteria in the assessment of integrated water management in the Aras catchment area', Hafezparast et al. (2015) emphasized the integrated management in the river basin and discussed the amount of investment and increase of irrigation efficiency as to have significant effects on the balance 
and sustainability of the basin. In another study entitled 'Patterns of water resources management', Jafarian et al. (2016) aimed at establishing an integrated water resources management system in Garmsar plain, with the perceived lack of institutional coherence among water resources management, water resources sustainability and system resilience. As they argued, an integrated water resources management network is achievable despite the current shortcomings.

In line with the above studies, Safavi and Rastghalam (2016) referred to a strategy to deal with the outbreak of a water crisis in the Zayandehrood watershed using integrated management. With a belief in the efficacy of managing water supply and water consumption, they states that this type of water management ensures the sustainability of water resources in the Zayandehrood basin from Zardkuh to Gavkhoni wetland.

The results of the present research and other scientific research such as the evaluation of high-level rules and documents in water resources management in Iran by Jamali (2017) show that executive rules and regulations as well as precise definitions of the tasks and scope of the mechanisms are needed to be implemented for managing water in catchment areas at the national level. Also, the customary practices of micro-level exploitation through the use of reusable planning techniques are recommended in order to identify the legal relationships between the operators and the water management bodies. In this way, a water governance system can be developed in the integrated management framework (Figure 1).

\section{Discussion}

In order to practice the integrated management of water resources of the country as delineated in paragraph 10 of the strategic objectives of the water sector and approved by the board of ministers of the Islamic Republic of Iran in 2003, the water management structure and implementation should be decentralized through increasing the participation of the public as well as local and environmental organizations in water cycles. Also, catchment areas should be considered as natural units of water management and provincial units for the activity of exploiters. In this way, the management of water resources can be improved in accordance with the enacted laws and regulations. The macro and micro levels of this issue should be designed and organized. In this study, the intermediate structure of integrated management was discussed initially at the level of catchment areas and sub-basins and then in terms of the provincial system to the lowest levels.
With regard to the fundamental features of rural economy, the dominant governance of agricultural utilization, and the emergence of crises in water resources, it is essential to devise a system for the integrated management of those resources in large agricultural areas (e.g. cultivated plains) and small areas in rural areas. To institutionalize integrated water resources management, there is a need for participatory planning techniques as well as the synergy and structural links between governmental organizations and rural people as the key stakeholders. This managerial pattern must structurally involve informed, all-inclusive, continuous participations. Based on recent studies in the rural areas of the northeast, southeast, and north of the country, there is model of participatory management derived to encompass community participation along with techniques for Participatory Rural Assessment (PRA). In this model, through the establishment of stakeholder groups and, in particular, exploiters, the structure of a participatory system is formed, and focused group discussions (FGDs) are organized and run under the guidance of rural governance.

As the first phase of this structure, experienced rural people get the benefit of the help from specialists to organize working groups of experts in rural settlements. The task of these working groups is, firstly, the pathology of issues and problems of water resource development as related to certain fields of practice. In this way, each working group prioritizes the problems of each sector involved. Then, by providing the necessary initial information, the groups prepare a series of projects with the assistance of local experts. The next step in this system is to determine the status and the manner of implementing the projects in terms of timing, sources of credit, and assistance of the corresponding government agencies and villagers. The second phase of activities in this organizational structure relates to tasks beyond the suburban level, where the projects of each working group are reviewed at the unit level of work. In this way, the projects that are subject to major constraints are removed from the list of the proposed projects. In the third phase, this organizational structure serves as an executive organization with an inter-institutional entity in main sub-basins. At this level of planning, the existential, operational and executive dimensions of each project are measured and evaluated. The fourth phase of this organizational structure is the participation of villagers, which is linked to the headquarters of governors in watersheds. At this final level, the projects proposed by villagers are evaluated by their priority and impact on sustainable rural water systems. Then, they are presented to the Strategic Integrated Management Committee, which makes the core policies 
of the integrated management of water in the catchment area.

At this stage, the proposed projects are evaluated for their strategic objectives in the sustainable rural water system. The evaluation is based on the opinions of provincial rural experts if a catchment area is located in two or more different provinces. In short, a set of operations is determined for rural water development projects in each rural settlement. After this stage, the proposed projects return to the working groups in rural settlements with the same mechanism. They are then implemented with the cooperation of expert as well as rural experts and real beneficiaries of those projects such as villagers.
In this institutionalized system of participation, it is anticipated that, following the implementation of the projects by each working group after two years, the projects will be evaluated with the participation of the villagers, and the results of the evaluation will be re-considered in the working group as new projects based on the issues that emerge, either as problems or as success of the water resources management programs.

Thus, a participatory model of making development plans is put to practice based on the ecological and socioeconomic capacities of a given rural area. This is possible only with the active participation of both villagers and local experts in rural development programs.

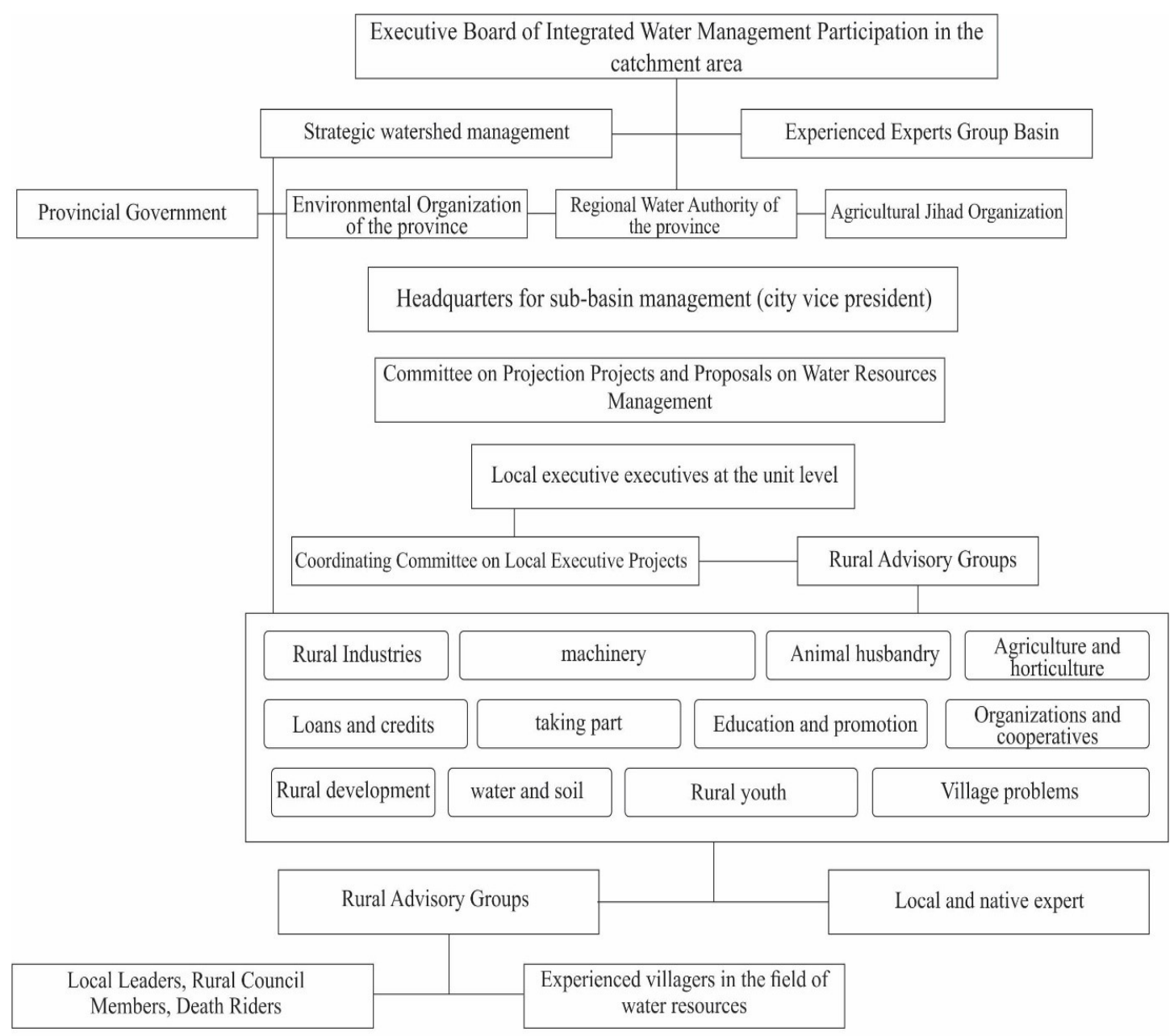

Figure 1. The organizational structure is a conscious, all-inclusive and sustainable 


\section{Acknowledgements}

This research did not receive any specific grant from funding agencies in the public, commercial, or not-forprofit sectors.

\section{Conflict of Interest}

The authors declared no conflicts of interest.

\section{References}

Abbaspour, Majid (2003) Environmental Engineering, Islamic Azad University Press

Azkia Mostafa and Valiollah Rostamiezadeh (2014); Social aspects of irrigation system in Iran, Journal of Anthropology / 12th year, No. 21, Autumn and Winter 2014

Brown, C, Lall ,U(2006) Water and economic development, The role of resilience for framework a and variability Natural, Forum Resources, Vol 30, pp 317-306

Clausen, T. (2005) "Integrated water Resources Management and water efficiency plans", IWRM.

Engle. N. et al (2011) Integrated and adaptive management of water resources: legacies and the next best thing, society and Ecology, Vol 16,NO 1,PP 1-11

Ferreyra, C., de loe, R.C \& Kreutzwiser. (2008) Imagined Communities contested watersheds: challenges to integrated water resources management in agricultural areas, Journal of rural studies, Vol 24,NO 3,PP 304-321

Hafezparast, Maryam, Nahayat Iraqi Nezhad and Salman Sharif Azari (2015); Sustainability criteria in assessing integrated water resources management in the Aras valley basin based on the DPSIR approach. NIS of Water and Soil Conservation Studies, Vol. 22, No. 22, 61- 77

IWRM for Sustainable Use for water, 50 years of International experience with the concept of IWRM, (2004), Ministry of Agriculture Nether Lands.

Jafarian, Vahid, Mohammad Reza Yazdani, Mohammad Rahimi and Mehdi Ghorbani (2016); Network Analysis of the Power Structure of Managers of Water Resources Management in Garmsar Plain, Iranian Journal of Water Resources Research, No. 3, Autumn 2016, 129-124

Jamali, Sadegh (2017); Legal and institutional barriers to the establishment of Integrated Water Resources Management in Iran's Water Management System; The First Consultation Meeting with Environmental and Water Sciences Specialists, Ministry of Energy

Jamab Consultant Engineers (1999); Water Comprehensive Plan, 28 volumes; Ministry of Energy

Maknon, Reza (2003); Comprehensive Approach to Water Resources, a Strategic Plan for the Fourth Development Plan of the Country, "Bulletin No. 11, National Committee for Sustainable Development,

Misra R. P. And Jay Shiverhma (1995), Public Participation, Jihad No. 89, 6th Year, Tehran

Musavi Nejad Moghadam, Babak (2004), Traditional structures of popular participation in rural communities, Research Center for Rural Issues, Ministry of Jihad-e-construction, Tehran

Poorasghar Sangachin, Farzam (2004); Reviewing the Challenges of Water Resources Management, Journal of Program and Budget, No. 67

Safavi, Hamid Reza and Mehdi Rast Kalam (2016); A solution to the water crisis in the Zayandehrood catchment area; Water supply and use management, Water Resources Researches Journal, No. 4, 22-12

Taleshi, Mostafa (2006) The role of P. R. A in sustainable rural development, Research project of Payame Noor University, Tehran

Taravati.H \& Ayafat.S.A (1998) A GENDA 21,A Sustainable Development Agenda for the 21 st century,Department of the Environment,Iran

Wight, P. (1996). North American ecotourism markets: Motivations, preferences, and destinations. Journal of Travel Research, 35(1), 3-10.

Zargarpour, Rasool and Nourzad Ali (2009) Presentation of Conceptual Model and Development of Integrated Water Resources Management Model with Emphasis on Water Security of Iran, Iranian Journal of Water Resources Research Volume 5, Number 3, pp. 13-1 
